\title{
Comunicação/Communication
}

\section{Ação ovicida do extrato bruto enzimático do fungo Pochonia chlamydosporia sobre ovos de Ancylostoma sp}

\author{
Ovicidal action of a crude enzymatic extract of fungus Pochonia chlamydosporia against \\ Ancylostoma sp eggs
}

\section{Fabio Ribeiro Braga ${ }^{1}$, Juliana Milani Araujo ${ }^{1}$, André Ricardo e Silva ${ }^{1}$, Jackson Victor de Araújo ${ }^{1}$, Rogério Oliva Carvalho $^{1}$, Filippe Elias de Freitas Soares ${ }^{2}$, José Humberto de Queiroz ${ }^{2}$ e Hugo Leonardo André Gênier ${ }^{2}$}

\begin{abstract}
RESUMO
Introdução: Ancylostoma sp é um geo-helminto potencialmente zoonótico. Métodos: $\mathrm{O}$ objetivo deste trabalho foi avaliar in vitro a ação do extrato bruto enzimático de Pochonia chlamydosporia (VC4) sobre ovos de Ancylostoma sp, em meio ágar-água $2 \%$ e em cultura de fezes. Resultados: Observou-se um percentual de redução na eclosão dos ovos de Ancylostoma sp, de 76,8\% na placas de Petri do grupo tratado em relação ao grupo controle. Conclusões: O extrato bruto enzimático de Pochonia chlamydosporia foi eficiente na redução da eclosão dos ovos de Ancylostoma sp, podendo ser utilizado como controlador biológico desse nematoide.
\end{abstract}

Palavras-chaves: Pochonia chlamydosporia. Crude enzymatic extract. Ancylostoma sp.

\begin{abstract}
Introduction: Ancylostoma sp is a potentially zoonotic geohelminth. Methods: This study aimed to evaluate in vitro the action of crude enzyme extract of Pochonia chlamydosporia (VC4) on eggs of Ancylostoma sp in $2 \%$ water-agar and in fecal cultures. Results: The percentage reduction in Ancylostoma sp egg eclosion was $76.8 \%$ in Petri dishes of the treated group compared to the control group. Conclusions: The crude enzyme extract of Pochonia chlamydosporia was effective at reducing Ancylostoma sp egg eclosion and can be used as biological control of this nematode.
\end{abstract}

Keywords: Pochonia chlamydosporia. Enzymes. Ancylostoma sp.

Ancylostoma caninum e o Ancylostoma braziliense, geohelmintos intestinais de cães e gatos, têm requerido grande atenção devido ao seu potencial zoonótico por meio direto da contaminação do solo com as fezes de animais parasitados. Nos cães e nos gatos, estes parasitas gastrintestinais podem causar anemia, diarréia, perda de peso, enterite hemorrágica, depressão e mesmo a morte ${ }^{1}$. Ainda segundo Crompton ${ }^{2}$ e Santarém e cols ${ }^{3}$, estima-se que mais de 1 bilhão de pessoas no mundo são infectadas por geo-helmintos por meio do solo, sugerindo, portanto que a contaminação ambiental é um importante indicador do risco da população humana de contrair estas infecções. Áreas públicas, como os parques e praças, são os principais locais de contaminação por ancilostomatídeos em crianças com idade pré-escolar. Nos humanos, o Ancylostoma braziliense e o

1. Departamento de Veterinária, Universidade Federal de Viçosa, Viçosa, MG. 2. Departamento de Bioquímica e Biologia Molecular, Universidade Federal de Viçosa, Viçosa, MG.

Endereço para correspondência: Dr. Fabio Ribeiro Braga. Dept ${ }^{\circ}$ de Veterinária/ UFV. Av. Ph Rolfes s/n, 36570-000 Viçosa, MG.

Tel: 5531 3899-1458

e-mail: fabioribeirobraga@hotmail.com

Recebido para publicação em 05/03/2010

Aceito em 01/09/2010
Ancylostoma caninum são responsáveis pela patologia denominada larva migrans cutânea, doença caracterizada por erupções lineares serpiginosas progressivas que se prolongam pelo tecido subcutâneo causada pela migração das larvas de terceiro estádio $\left(\mathrm{L}_{3}\right)$ destes vermes, que permanecem no solo durante semanas ou meses ${ }^{4}$. Dessa forma, métodos de prevenção e alternativas de controle de geo-helmintos que sejam implantados para reduzir a contaminação ambiental das formas infectantes e de seus ovos são importantes ${ }^{5}$. Dentre essas alternativas sugere-se o controle biológico com fungos nematófagos, que são os principais antagonistas naturais dos nematoides no solo contaminado. São divididos em predadores, endoparasitas e ovicidas. No grupo de fungos ovicidas, destacamse a espécie Pochonia chlamydosporia (VC4) que produz enzimas extracelulares do tipo proteases que desenvolvem um papel importante na infecção e na destruição (atividade ovicida) dos ovos de geo-helmintos ${ }^{6}$. De acordo com Esteves e cols ${ }^{7}$, alguns trabalhos têm demonstrado que isolados fúngicos de Pochonia chlamydosporia são capazes de produzir extratos enzimáticos contra vários tipos de substratos sólidos, e dentre esses, os polissacarídeos, as proteínas e os lipídios. Além disso, sua ação ovicida tem sido testada com sucesso contra ovos de vários gêneros de geo-helmintos em condições laboratoriais e a campo ${ }^{5,8}$. Contudo, seu extrato bruto enzimático nunca foi testado sobre ovos de geo-helmintos, e dentre esses de Ancylostoma sp, constituindo dessa forma, uma alternativa de controle.

O objetivo deste trabalho foi avaliar in vitro a ação do extrato bruto enzimático do fungo Pochonia chlamydosporia (VC4) em distintos ensaios sobre ovos de Ancylostoma sp.

Foi utilizado um isolado de fungo ovicida Pochonia chlamydosporia (VC4) da micoteca do Laboratório de Parasitologia do Departamento de Veterinária da Universidade Federal de Viçosa, Minas Gerais, Brasil mantido em tubos de ensaio a $4{ }^{\circ} \mathrm{C}$ contendo corn-meal-ágar 2\% (CMA2\%) no escuro e durante 10 dias. A seguir, procedeu-se o cultivo fúngico em frascos erlenmeyers com 50ml de meio mínimo liquido (0,3g l/1 $\mathrm{NaCl}$, 0,3gl/1 MgSO 4.7H2O, 0,3g l-1 K2HPO4 e 0,2gl/ 1 do extrato de levedura) e suplementado com $0,2 \%$ de gelatina. A gelatina foi filtrada por meio de filtro milipore $(45 \mu \mathrm{m})$ antes de ser adicionada de forma asséptica no meio autoclavado. As amostras contendo o isolado foram incubadas no escuro a $28^{\circ} \mathrm{C}$ em agitador rotatório a $120 \mathrm{Xg}$ e após cinco dias o sobrenadante foi coletado e filtrado, usando papel filtro Whatman $\mathrm{n}^{\circ} 1$ a $4^{\circ} \mathrm{C}$ de acordo técnica descrita por Esteves e cols ${ }^{7}$.

Os ensaios experimentais in vitro, denominados de $\mathrm{A}$ e $\mathrm{B}$, foram realizados em etapas distintas durante um intervalo de 8 dias. 
No ensaio A, avaliou-se a atividade do extrato bruto enzimático de Pochonia chlamydosporia (VC4) sobre a eclosão de ovos de Ancylostoma sp, em placas de Petri. No ensaio B, avaliou-se a ação enzimática de extrato bruto obtido de VC4 sobre a eclosão dos ovos de Ancylostoma sp, presentes em amostras fecais. Cerca de $500 \mathrm{~g}$ de fezes frescas de cães naturalmente infectados foram coletadas. Esse material fecal utilizado foi dividido em duas partes contendo cerca de $250 \mathrm{~g}$ cada uma. A primeira parte foi utilizada para a remoção de ovos por meio da técnica de flutuação fecal. A seguir, esses ovos foram centrifugados em água destilada. O conteúdo presente no tubo de centrifuga foi homogeneizado e deste foram retiradas três alíquotas de $10 \mu \mathrm{l}$. Os ovos foram contados com auxílio de estereomicroscópio e aumento de 10x. A quantidade total desses ovos foi estimada de acordo com Araújo e $\mathrm{cols}^{9}$. A segunda parte das fezes foi utilizada para a realização do ensaio experimental B, na confecção das coproculturas.

No ensaio A, mil ovos de Ancylostoma sp, foram vertidos para placas de Petri de 4,5cm de diâmetro com $5 \mathrm{ml}$ de extrato bruto de Pochonia chlamydosporia (VC4) constituindo o grupo tratado. O grupo controle continha apenas 1.000 ovos em 10ml de água destilada na placas de Petri. As placas de Petri dos grupos tratado e controle foram vedadas com película Rolapack e incubadas a $26^{\circ} \mathrm{C}$ e no escuro por $24 \mathrm{~h}$. Cada tratamento, foi constituído por seis repetições. Após o período de $24 \mathrm{~h}$, foi contado o número total de larvas de Ancylostoma sp, presentes em cada placa de Petri dos grupos tratado e controle de acordo com a metodologia descrita por Mukhtar e Pervaz ${ }^{10}$. No ensaio B, cerca de $20 \mathrm{~g}$ de fezes positivas foram misturadas com vermiculita industrial fragmentada (autoclavada) e umedecidas. A seguir, foram adicionados $10 \mathrm{ml}$ de extrato bruto de Pochonia chlamydosporia (VC4) e levadas à estufa a $26^{\circ} \mathrm{C}$ e durante 8 dias, constituindo o grupo tratado. $\mathrm{O}$ grupo controle foi constituído apenas pelas coproculturas sem o extrato enzimático bruto de Pochonia chlamydosporia. Ao final desse período, foram obtidas larvas de terceiro estádio $\left(\mathrm{L}_{3}\right)$ pelo método de Baermann, que foram identificadas e quantificadas segundo os critérios descritos por Urquhart e cols ${ }^{11}$ em microscópio óptico e objetiva de 10x. A leitura do Baermann demonstrou que $100 \%$ das larvas visualizadas eram de Ancylostoma sp.

Os dados obtidos nos ensaios experimentais A e B, foram interpretados estatisticamente pela análise de variância em níveis em níveis de significância de 1 e $5 \%$ de probabilidade. A eficiência de eclosão dos ovos em relação ao controle foi avaliada pelo teste de Tukey ao nível de $1 \%$ de probabilidade. Posteriormente, o percentual de redução da média de larvas foi calculado de acordo com a seguinte equação:

$\%$ redução $=($ média de larvas do controle - médias de larvas do tratamento $) \times 100$ média de larvas do controle

Nas placas de Petri do grupo tratado, com o extrato bruto enzimático de Pochonia chlamydosporia (VC4), observou-se após $24 \mathrm{~h}$ de interação, a presença de larvas e de ovos de Ancylostoma $\mathrm{sp}$, com alterações morfológicas que não eclodiram. Contudo, no grupo controle foram observadas apenas larvas eclodidas após o mesmo intervalo de tempo. Diferença $(\mathrm{p}<0,01)$ foi encontrada entre o número de larvas nas placas do grupo tratado e grupo controle (Figura 1). Além disso, houve um percentual de redução na eclosão dos ovos de Ancylostoma sp, de 76,8\% na placas de Petri do grupo tratado em relação ao grupo controle. Ao final de oito dias, ensaio $\mathrm{B}$, a análise das culturas de fezes realizadas demonstrou, que o extrato bruto enzimático de Pochonia chlamydosporia foi eficiente na redução do número de $\mathrm{L}_{3}$ de Ancylostoma sp, por meio da técnica

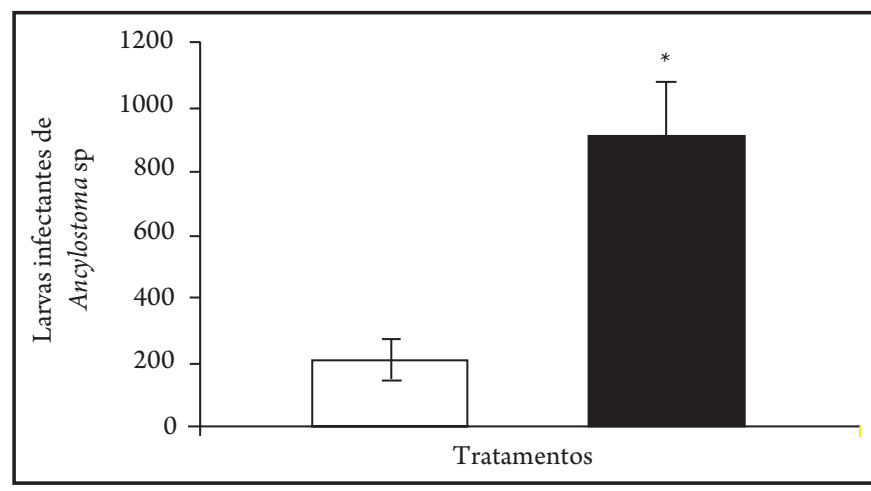

FIGURA 1 - Valores médios das larvas de Ancylostoma sp recuperadas das placas de petri do grupo tratado com o extrato bruto enzimático do fungo $\square$ Pochonia chlamydosporia (VC4) e do grupo controle日, após 24 horas de interação. Diferença significante $(\mathbf{p}<0,01)$ entre o grupo tratado com fungo e controle *Teste de Tukey.

de Baermann (Figura 2). Ao final desse ensaio, houve diferença $(\mathrm{p}<0,01)$ entre as médias de larvas recuperadas do grupo tratado em ralação ao grupo controle com um percentual de redução de 67,9\% no grupo tratado. No presente trabalho, demonstrou-se a atividade do extrato bruto enzimático de Pochonia chlamydosporia (VC4) na eclosão de ovos de Ancylostoma sp, ao final do ensaio experimental A. Esse resultado está de acordo com Esteves e cols ${ }^{7}$, que trabalharam com esse mesmo fungo crescido em meio líquido suplementado com gelatina $0,2 \%$ e, posteriormente, demonstraram sua ação na eclosão de ovos de Meloidogyne sp, um fitonematoide.

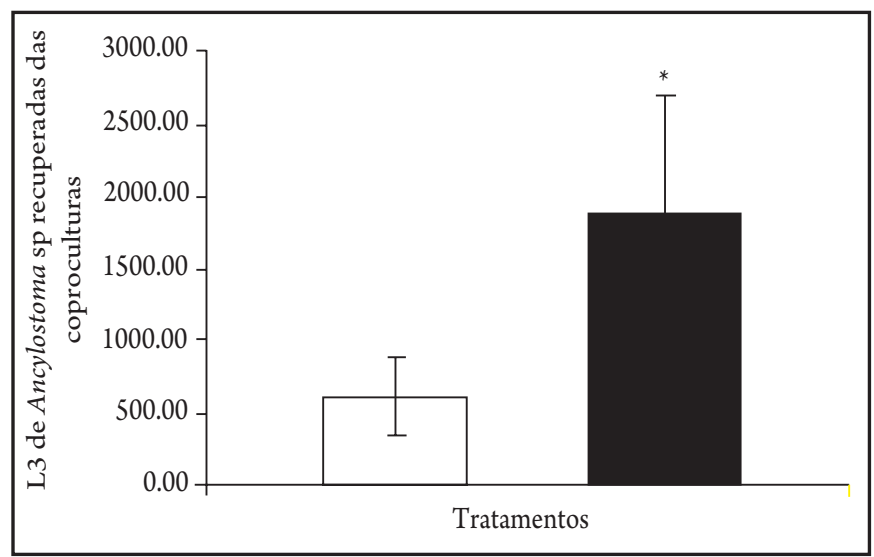

FIGURA 2 - Valores médios das larvas de Ancylostoma sp recuperadas das coproculturas do grupo tratado com o extrato bruto enzimático do fungo $\square$ Pochonia chlamydosporia (VC4) e do grupo controle $\square$, após 8 dias. Diferença significante $(p<0,01)$ entre o grupo tratado com fungo e controle ${ }^{*}$ Teste de Tukey.

Após 24h de incubação, os autores do presente trabalho, observaram que as larvas de Ancylostoma sp, estavam ativas e sem paralisia. No entanto, durante o ensaio experimental a toxicidade do extrato bruto de Pochonia chlamydosporia (VC4) não foi estimada pelo número de nematoides paralisados. Por outro lado, Mukhtar e Pervaz ${ }^{10}$ registraram que a ação do filtrado fúngico de Pochonia chlamydosporia sobre juvenis de Meloidogyne javanica, um fitonematoide, provocou a mortalidade de 13,2\% das larvas após o mesmo intervalo estudado. Estes autores mencionaram que a toxicidade do filtrado fúngico utilizado foi estimada de acordo com o percentual médio de nematoides paralisados. Contudo, os resultados encontrados no presente trabalho não estão de acordo com o trabalho de Mukhtar e Pervaz ${ }^{10}$, sugerindo que isso possa ter ocorrido 
devido às diferentes condições de cultura e a utilização de nematoides gastrintestinais e não de fitonematoides. Esteves e cols ${ }^{7}$ mencionam que pode haver diferenças sobre os resultados obtidos na produção de enzimas entre vários isolados do fungo Pochonia chlamydosporia. Além disso, esses autores relataram que as condições de cultura parecem ter um importante papel e isso deve sempre ser padronizado para que comparações significativas possam ser realizadas. Ainda de acordo com Mukhtar e Pervaz ${ }^{10}$ a ação nematicida do filtrado de Pochonia chlamydosporia sobre juvenis de Meloidogyne javanica pode ser atribuída com a produção de certas enzimas e toxinas do tipo verticillim $\mathrm{A}, \mathrm{B}$ e C que ajudam a enfraquecer e dissolver a cutícula dos nematoides. Recentemente, Braga e $\operatorname{cols}^{8}$ demonstraram a viabilidade desse fungo após passagem pelo trato gastrintestinal de equinos e comprovaram sua capacidade ovicida sobre ovos de Oxyuris equi, nematoide gastrintestinal de equinos, ao final do ensaio. Contudo, existe uma carência de trabalhos que possam evidenciar a ação de Pochonia chlamydosporia sobre larvas infectantes de nematoides gastrintestinais de animais domésticos e, mais pesquisas são necessárias.

O fungo Pochonia chlamydosporia produz uma protease (VCP1) responsável pela destruição dos ovos de fitonematoides. Contudo, esse é o primeiro relato da sua ação enzimática sobre ovos de um geo-helminto. De acordo com Segers e cols ${ }^{12}$, a produção de VCP1 em meio liquido pelo fungo poderia ser suprimida, caso, fosse utilizada o substrato gelatina em altas concentrações. No presente ensaio experimental, o fungo Pochonia chlamydosporia (VC4) foi capaz de crescer em meio líquido suplementado com gelatina $0,2 \%$ demonstrando sua atividade proteolítica, no entanto, os autores não buscaram determinar a purificação enzimática, mas, produzir extrato bruto enzimático com ação proteolítica. Vários trabalhos têm mencionado o uso de Pochonia chlamydosporia (VC4) crescido em placas de Petri sobre ovos de geo-helmintos parasitas grastintestinais ${ }^{6}$. No entanto, este é o primeiro relato da ação do seu extrato bruto enzimático sobre ovos de Ancylostoma sp. Desta forma, por meio dos resultados obtidos no presente trabalho os autores sugerem que esse fungo poderia ser empregado no controle de ovos de geo-helmintos parasitos gastrintestinais que eclodem em curto intervalo de tempo no ambiente, partindo-se do principio que até o presente momento apenas ovos de helmintos com maior período de incubação no ambiente tinham sido alvo dos estudos, destacando-se Ascaris lumbricoides ${ }^{13}$. Em trabalho recente, Frassy e cols ${ }^{5}$ demonstraram a ação ovicida de Pochonia chlamydosporia crescido em meio AA 2\% sobre ovos de Toxocara canis, ascarídeo potencialmente zoonótico de cães, naquele trabalho, os autores registraram um percentual de redução de $43,8 \%$ em relação ao grupo controle. Contudo, no presente trabalho o uso do extrato bruto enzimático foi mais promissor, com um percentual de redução de $76,8 \%$ sobre ovos de Ancylostoma sp.

Segundo Braga e cols ${ }^{13}$, um fungo é caracterizado como ovicida se durante o processo de infecção dos ovos apresentar o efeito do tipo 3 (ação ovicida). O fungo Pochonia chlamydosporia (VC4) causou redução do número de $\mathrm{L}_{3}$ recuperadas das coproculturas ao final do ensaio B, com um percentual de $67 \%$ demonstrando sua atividade enzimática sobre ovos e possivelmente sobre alguns estádios das larvas, mesmo em material fecal. Em outro trabalho, Carvalho e cols ${ }^{14}$ demonstraram que a utilização de fungos nematófagos é uma medida promissora que contribui para a diminuição da contaminação ambiental de $\mathrm{L}_{3}$ de Ancylostoma sp. Naquele trabalho, os autores registraram uma redução de $66,8 \%$ das $\mathrm{L}_{3}$ recuperadas das coproculturas. Por meio dos resultados obtidos no ensaio B, sugere-se a empregabilidade de extrato bruto enzimático de Pochonia chlamydosporia sobre ovos de Ancylostoma sp. Contudo, os autores sugerem a caracterização das substâncias produzidas pelo fungo
Pochonia chlamydosporia (VC4) em trabalhos futuros. De acordo com Freitas ${ }^{15}$, o controle da ancilostomose, embora tecnicamente fácil, na realidade torna-se muito difícil. No entanto, dentre as medidas de saúde pública utilizadas, destaca-se a desinfecção do solo. Neste contexto, sugere-se o uso de fungos nematófagos, como uma alternativa de controle, uma vez que esses organismos estão naturalmente presentes no ambiente. Todavia, no futuro, maiores estudos sobre as atividades enzimáticas do fungo Pochonia chlamydosporia serão foco de outros trabalhos.

\section{CONFLITO DE INTERESSE}

Os autores declaram não haver nenhum tipo de conflito de interesse no desenvolvimento do estudo.

\section{SUPORTE FINANCEIRO}

Coordenação de Aperfeiçoamento de Pessoal de Nível Superior (CAPES), Fundação de Amparo à Pesquisa do Estado de Minas Gerais (FAPEMIG), Financiadora deEstudos e Projetos (FINEP) e Conselho Nacional de Desenvolvimento Científico e Tecnológico (CNPq).

\section{REFERÊNCIAS}

1. Robertson ID, Thompson RC. Enteric parasitic zoonoses of domesticated dogs and cats. Microb Infect 2002; 4:867-873.

2. Crompton DWT. How much human helminthiasis is there in the world? J Parasitol 1999; 85:397-403.

3. Santarém VA, Giuffrida R, Asin GA. Larva migrans cutânea: ocorrência de casos humanos e identificação de larva de Ancylostoma spp em parque público do município de Taciba, São Paulo. Rev Soc Bras Med Trop 2004; 37:179-181.

4. Brenner MA, Patel MB. Cutaneous larva migrans: the creeping eruption. Cutis 2003; 72:111-115.

5. Frassy LN, Braga FR, Silva AR, Araújo JV, Ferreira SR, Freitas LG. Destruição de ovos de Toxocara canis pelo fungo nematófago Pochonia chlamydosporia. Rev Soc Bras Med Trop 2010; 43:102-104.

6. Araujo JM, Araújo JV, Braga FR, Carvalho RO, Silva AR, Campos AK. Interaction and ovicidal activity of nematophagous fungus Pochonia chlamydosporia on Taenia saginata eggs. Exp Parasitol 2009; 121:338-341.

7. Esteves I, Peteira B, Atkins SD, Magan N, Kerry B. Production of extracellular enzymes by different isolates of Pochonia chlamydosporia. Mycol Res 2009; 113:867-876

8. Braga FR, Araújo JV, Silva AR, Carvalho RO, Araujo JM, Ferreira SR, et al. Viability of the nematophagous fungus Pochonia chlamydosporia after passage through the gastrointestinal tract of horses. Vet Par 2010; 168:264-268.

9. AraújoJV,Santos MA, FerrazS, MaiaAS. Antagonistic effect of predacious Arthrobotrys fungi on infective Haemonchus placei larvae. J Helminthol 1993; 67:136-138.

10. Mukhtar T, Pervaz I. In vitro evaluation of ovicidal and larvicidal effects of culture filtrate of Verticillium chlamydosporium against Meloidogyne javanica. Int J Agricult Biol 2003; 5:576-579.

11. Urquhart GM, Armour J, Duncan JL, Dunn AM, Jennings FW. Parasitologia Veterinária. $2^{\text {rd }}$ ed. Rio de Janeiro: Guanabara Koogan; 1988.

12. Segers R, Butt MT, Kerry BR, Beckett A, Peberdy JF. The role of the proteinase VCP1 produced by the nematophagous Verticillium chlamydosporium in the infection process of nematode eggs. Mycol Res 1996; 100:421-428.

13. Braga FR, Araújo JV, Campos AK, Carvalho RO, Silva AR, Tavela AO, et al. Observação in vitro da ação dos isolados fúngicos Duddingtonia flagrans, Monacrosporium thaumasium e Verticillium chlamydosporium sobre ovos de Ascaris lumbricoides (Lineu, 1758). Rev Soc Bras Med Trop 2007; 40:356-358.

14. Carvalho RO, AraújoJV,Braga FR, AraujoJM, Silva AR, Tavela AO. Predatory activity of nematophagous fungi on Ancylostoma ssp. infective larvae: evaluation in vitro and after passing through gastrointestinal tract of dogs. J Helminthol 2009; 15:1-5.

15. Freitas MG. Helmintologia veterinária. $4^{\text {rd }}$ ed. Belo Horizonte: Gráfica Rabelo; 1982. 